\title{
The effect of melt on the seismic anisotropy of ice polycrystalline aggregates
}

Maria-Gema Llorens ${ }^{1}$, Albert Griera 2 , Enrique Gomez-Rivas 3 , Paul D. Bons $^{4}$, Ilka Weikusat ${ }^{4,5}$, David Prior ${ }^{6}$ and Ricardo Lebensohn 7

${ }^{1}$ ICTJA-CSIC; ${ }^{2}$ Autonomous Univ. Barcelona; ${ }^{3}$ Univ. Barcelona; ${ }^{4}$ Univ. Tübingen; ${ }^{5} \mathrm{AWI} ;{ }^{6}$ Univ.

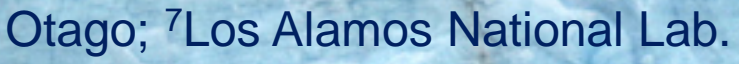

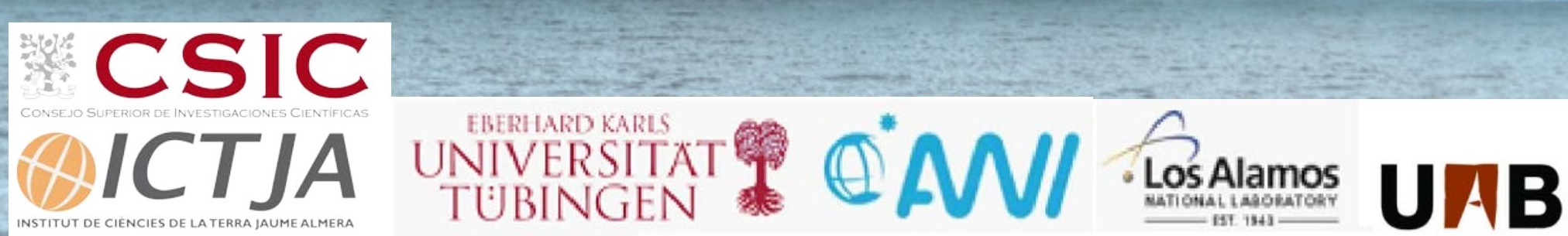


- Observations of P-wave (Vp) and S-wave (Vs) velocities in ice sheets reveal a strong decrease of $\sim 25 \%$ of $V s$ with depth, while $V p$ remains approximately constant

- The low Vs may be due to the presence of unfrozen liquids resulting from pre-melting at grain joints and/or melting of chemical solutions buried in ice (Wittlinger and Farra, 2015)

Although previous studies of two-phase rocks (including melt and water) show that seismic velocities depend on both CPO and water content, studies on the effect of melt on polar ice seismic velocity are scarce

Aim $\rightarrow$ Analyse polycrystalline ice with different melt fractions (temperate ice) through numerical simulations to:

- Understand how melt influences the development of microstructures

- Link the developed microstructures to the changes in P- and faster Swave velocities during ice deformation 


\section{Ice deformation mechanisms and rheology}

Ice is highly anisotropic: the critical resolved shear stress required to activate slip systems (CRSS) for non basal vs basal slip systems is $A>60$

Deformation is mainly accommodated by dislocation creep. Preferential glide on the basal plane and along the $<1120>$ direction
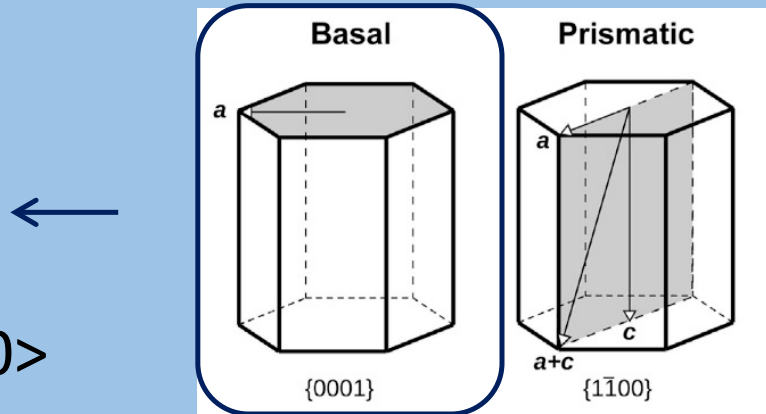

Pyramidal

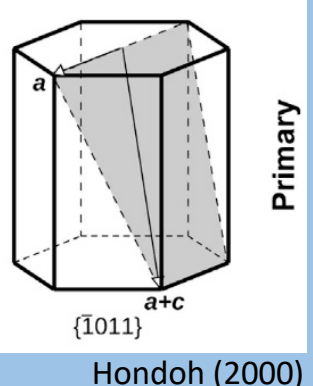

Viscoplastic deformation increases dislocation density and produces an increment of the internal strain energy. It can be reduced by:

- Recovery (annihilation of opposite dislocations and poligonisation)

- Recrystallisation (reduction of boundary energy and dislocation density) 
Objective: Simulate temperate ice deformation in simple shear using VPFFT (Full Field crystal plasticity code) + dynamic recrystallisation (DRX) processes (recovery, recrystallisation and polygonisation) in order to investigate the evolution of the microstructure and seismic velocity anisotropy during deformation

Simulation approach: ELLE is an open-source numerical simulation platform used to simulate the development of microstructures during tectonic and/or metamorphic processes.

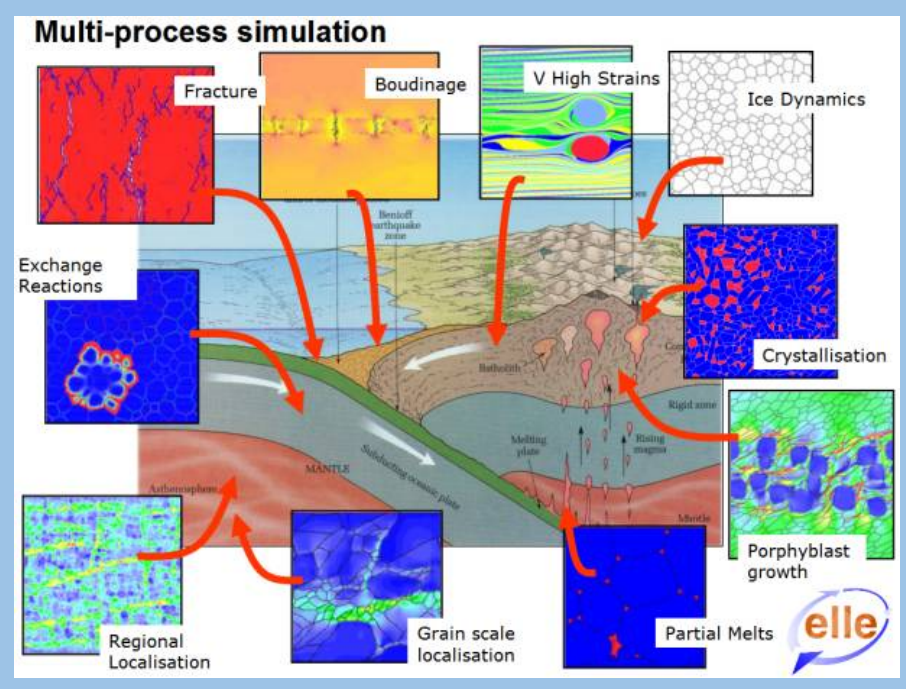

ELLE data layers: the initial microstructure in simple shear simulations is a square model

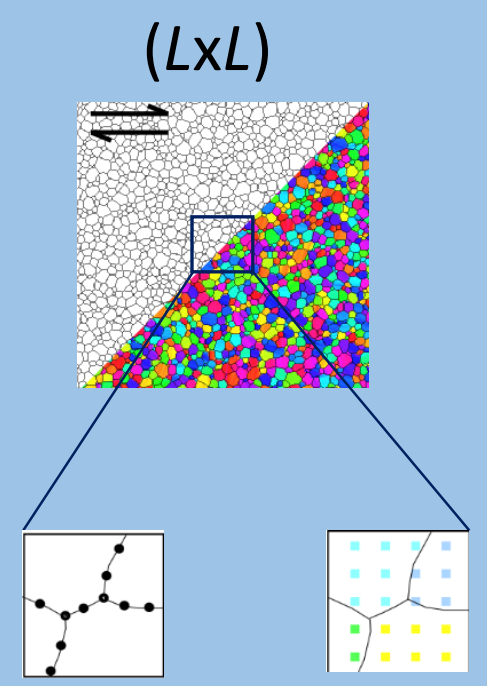

Boundary nodes Fourier points (define grains) (store properties) 
VPFFT (Viscoplastic full-field algorithm) solves the mechanical problem by finding the strain rate and stress field that minimize the average local workrate. Viscoplastic deformation is accommodated by dislocation glide

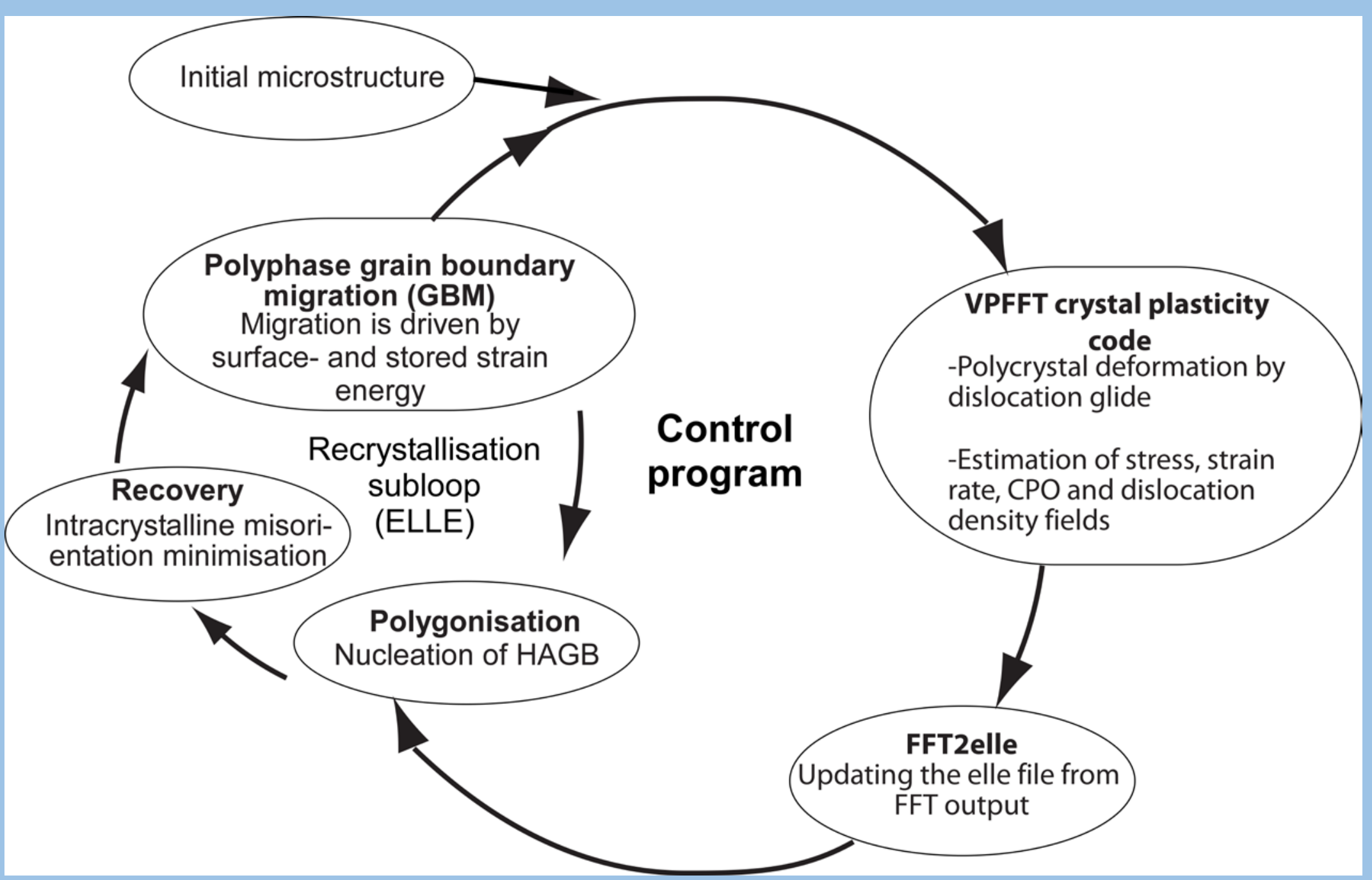




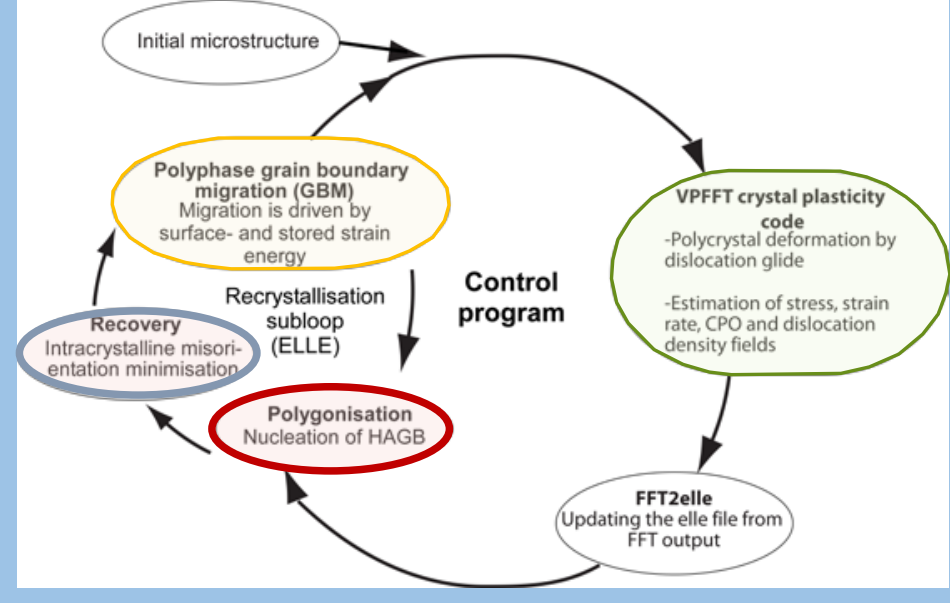

Recovery

Reduction internal misorientation

VPFFT (Viscoplastic full-field algorithm) (Lebensohn, 2001)

$$
\dot{\varepsilon}(\mathrm{x})=\dot{\gamma}_{0} \sum_{\mathrm{s}} \mathrm{m}^{\mathrm{s}}(\mathrm{x})\left(\frac{\mathrm{m}^{\mathrm{s}}(\mathrm{x}): \sigma^{\prime}(\mathrm{x})}{\tau_{0}^{\mathrm{s}}(\mathrm{x})}\right)^{\mathrm{n}}
$$
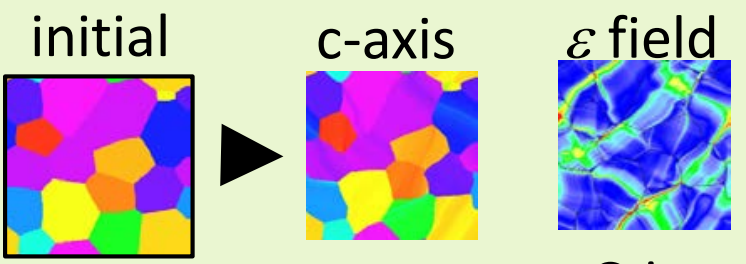

$\sigma$ field

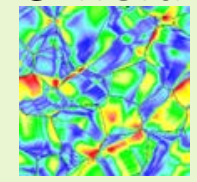

Griera et al. (2011)

\section{Polyphase GBM}

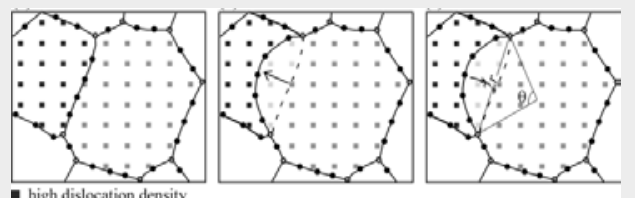

Reduction of the boundary energy

Reduction of the dislocation density

Steinbach et al. (2016); Llorens et al. (2019)

\section{Polygonisation}
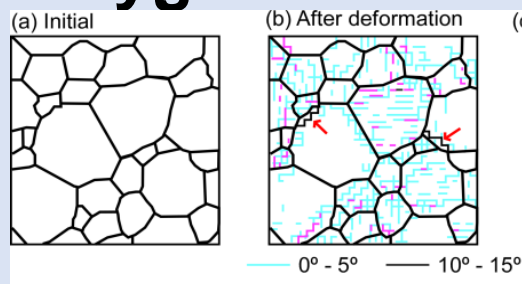

(c) Updated boundary network

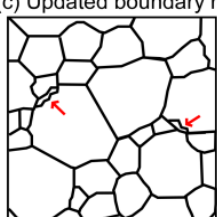

Identifies the high angle grain boundaries (HAGB) and updates the grain boundary network 
- Ice with 3 different melt fractions of $0 \%, 5 \%$ and $15 \%$ located at triple grain junctions

- Initial random distribution of c-axis orientation (bulk isotropic)

- Ice: $A=60$ (CRSS basal vs non-basal slip systems) and $n=3$ and melt $A=1$ and $n=3$

- Dextral simple shear increments of 0.02 shear strain up to 8

- Dynamic recrystallisation applied in a substep sequence repeated 10 times after deformation
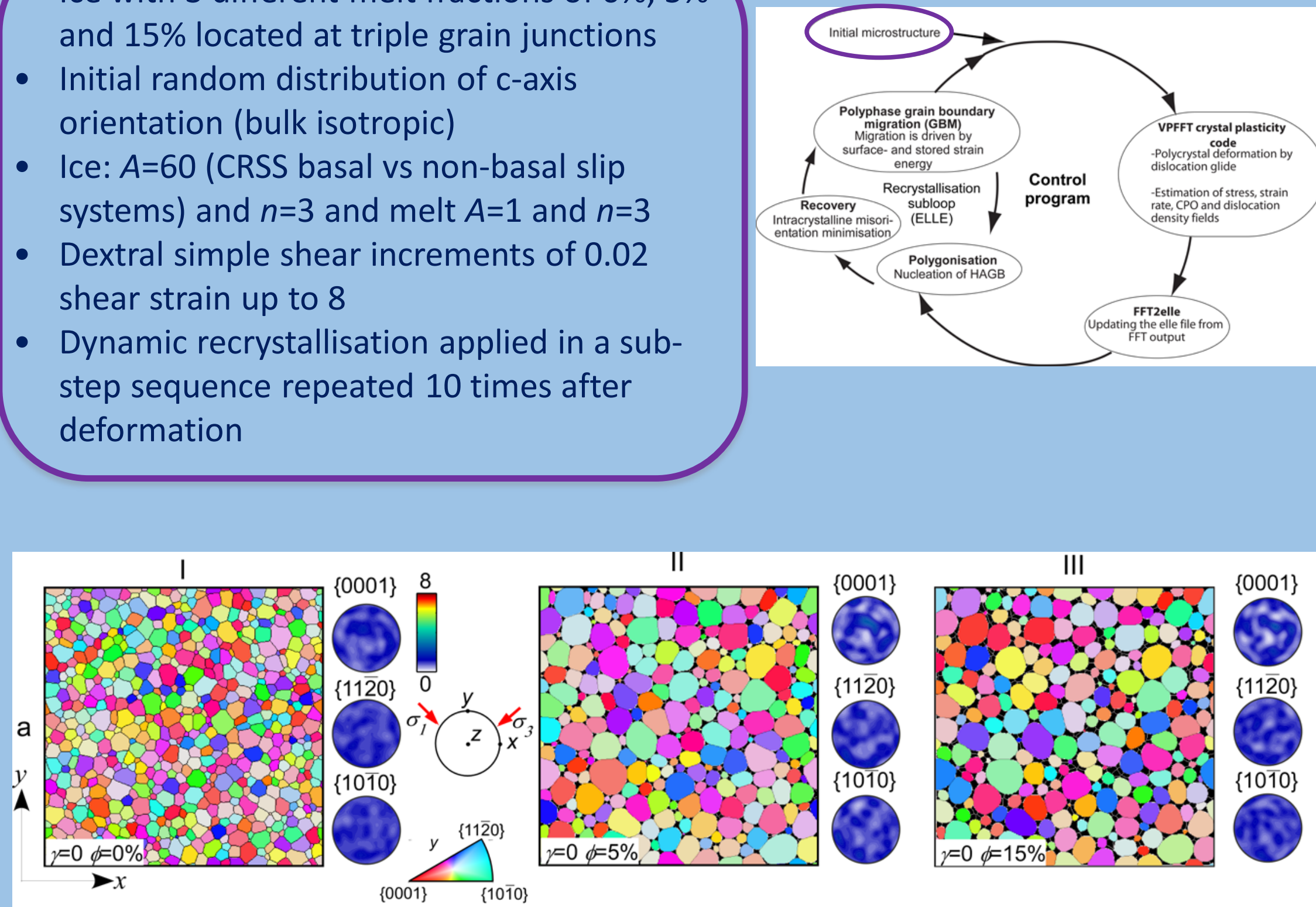

$\{0001\}$

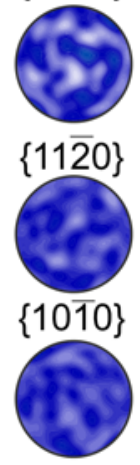




\section{Crystal Preferred Orientation evolution}

no melt $(\phi=0 \%) \quad$ with melt $(\phi=5 \%) \quad$ with melt $(\phi=15 \%)$
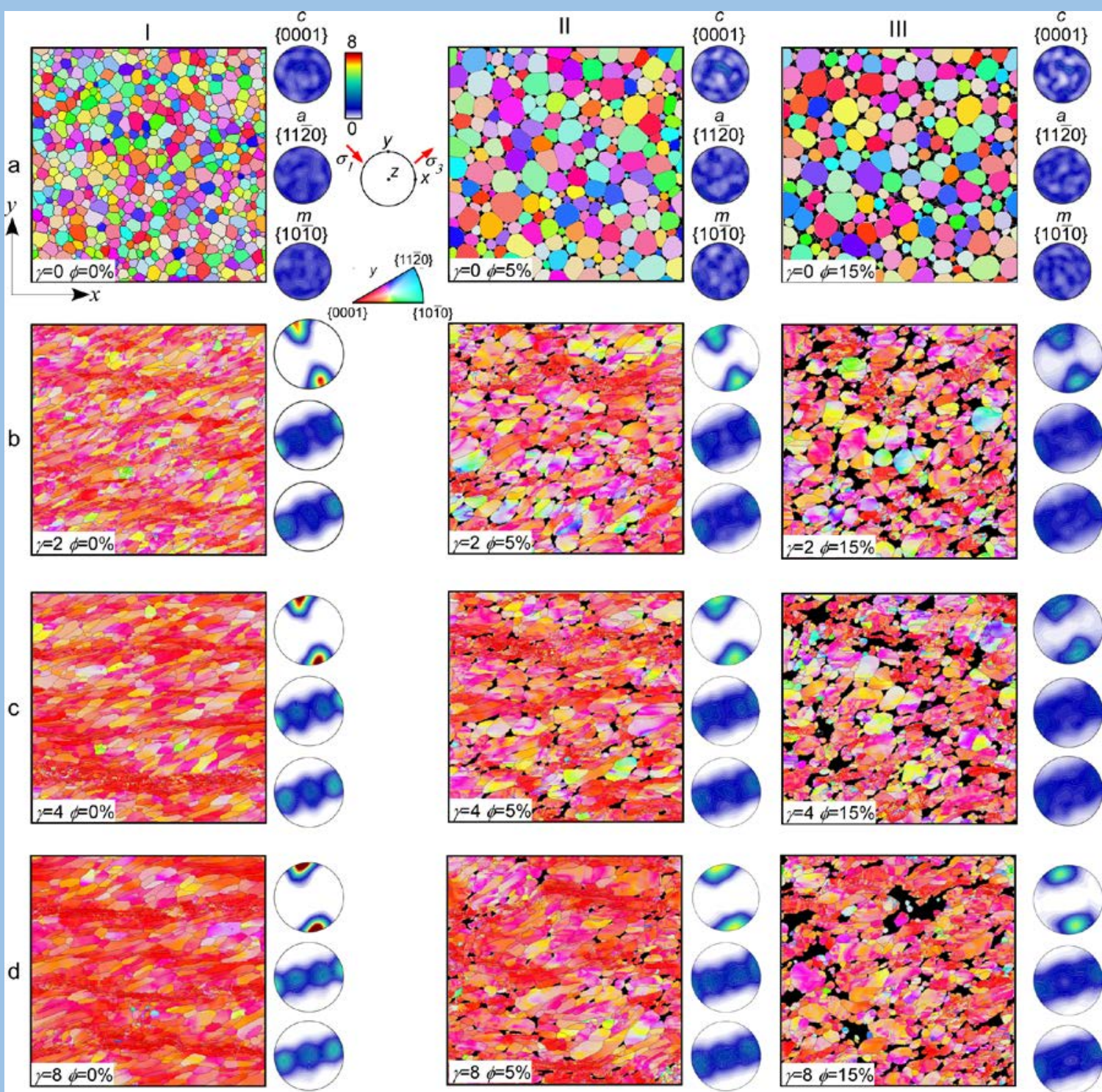
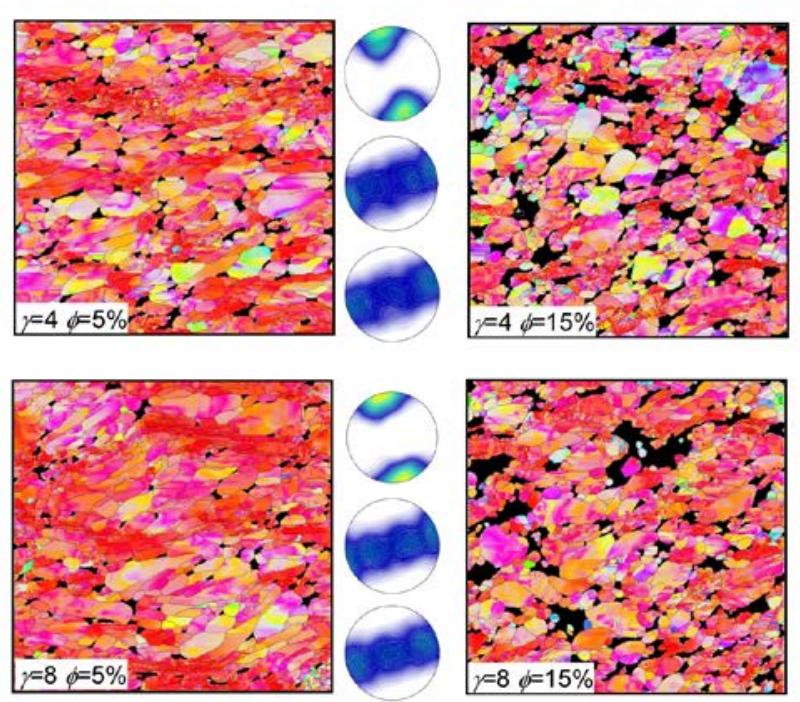

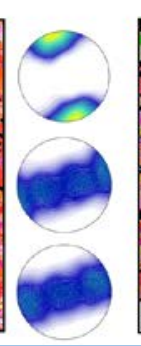

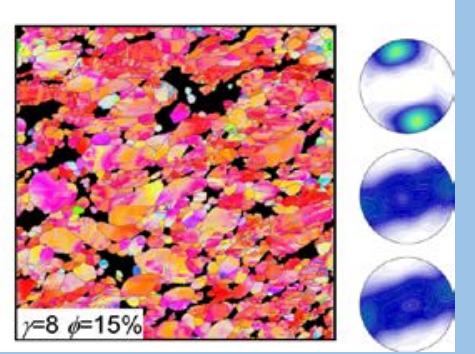

- Regardless the melt percentage $(\phi)$, all simulations evolve from a random fabric to a caxis preferred orientation (CPO) approximately perpendicular to the shear plane.

- When melt is present (columns II and III), the developed CPO is less intense than the pure ice simulation (I) 


\section{Calculation of P-wave and S-wave velocities}

Using the AEH-EBSD Analysis Toolbox (Vel et al., 2016)

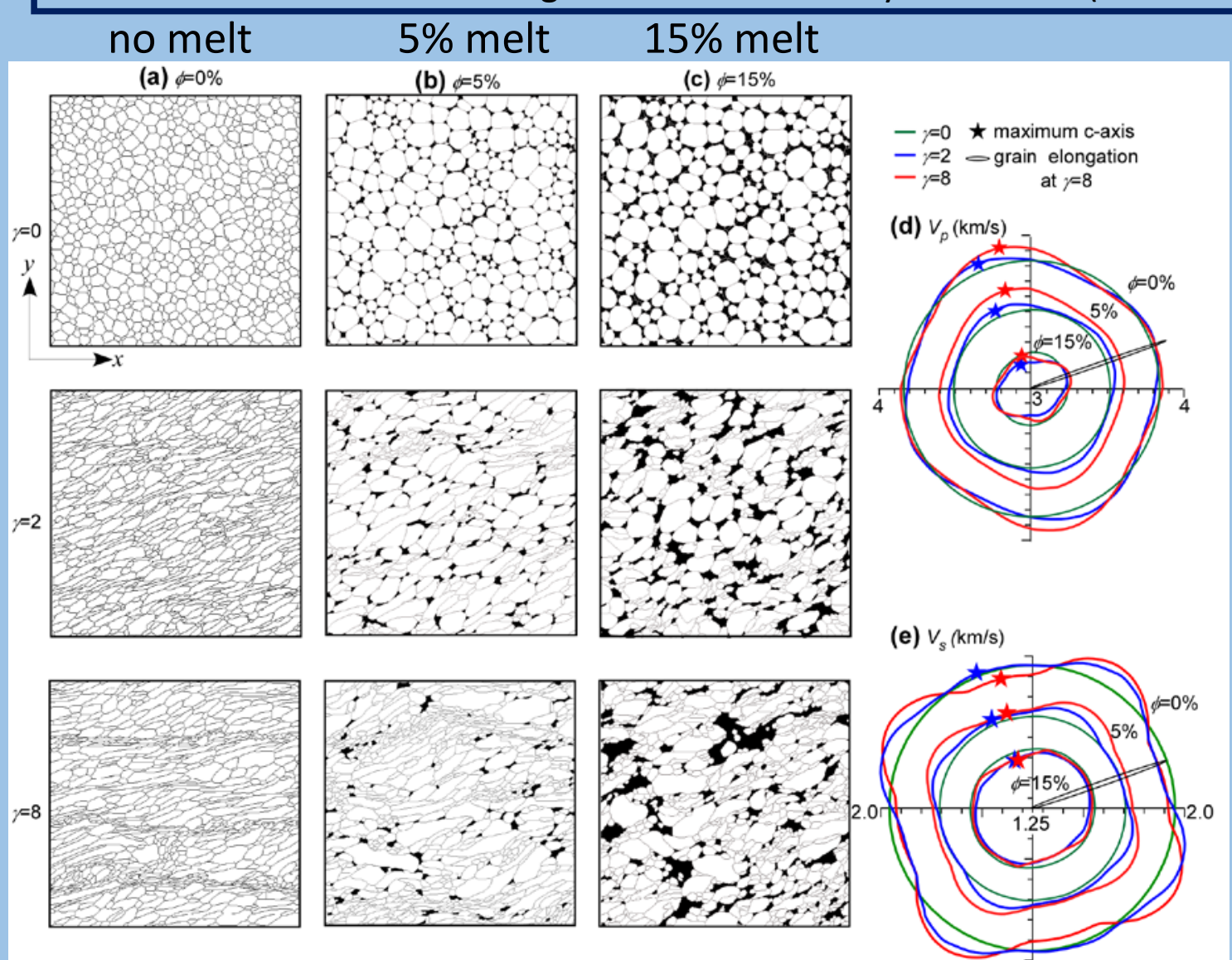

For zero melt ( $\phi=0 \%)$, the highest
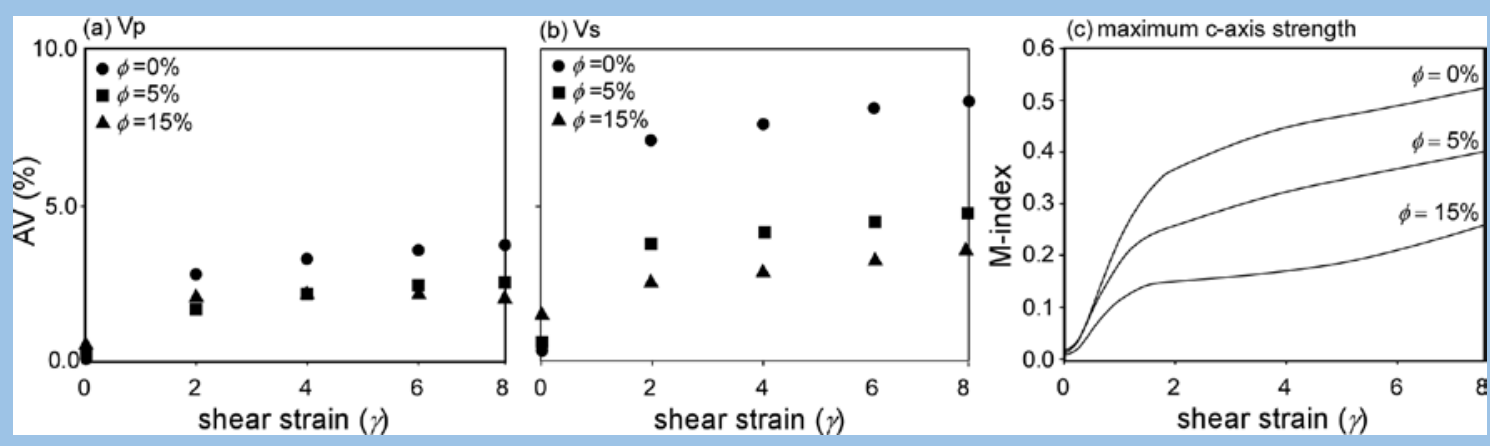

For all simulations the anisotropy of $V p$ and $V s$ increases up to $\gamma=2$. Higher anisotropies are observed in S-wave velocities. When water in present, the anisotropy of both $V p$ and $V s$ is reduced, as the developed maximum c-axis is less intense 


\section{Calculation of P-wave and S-wave velocities}

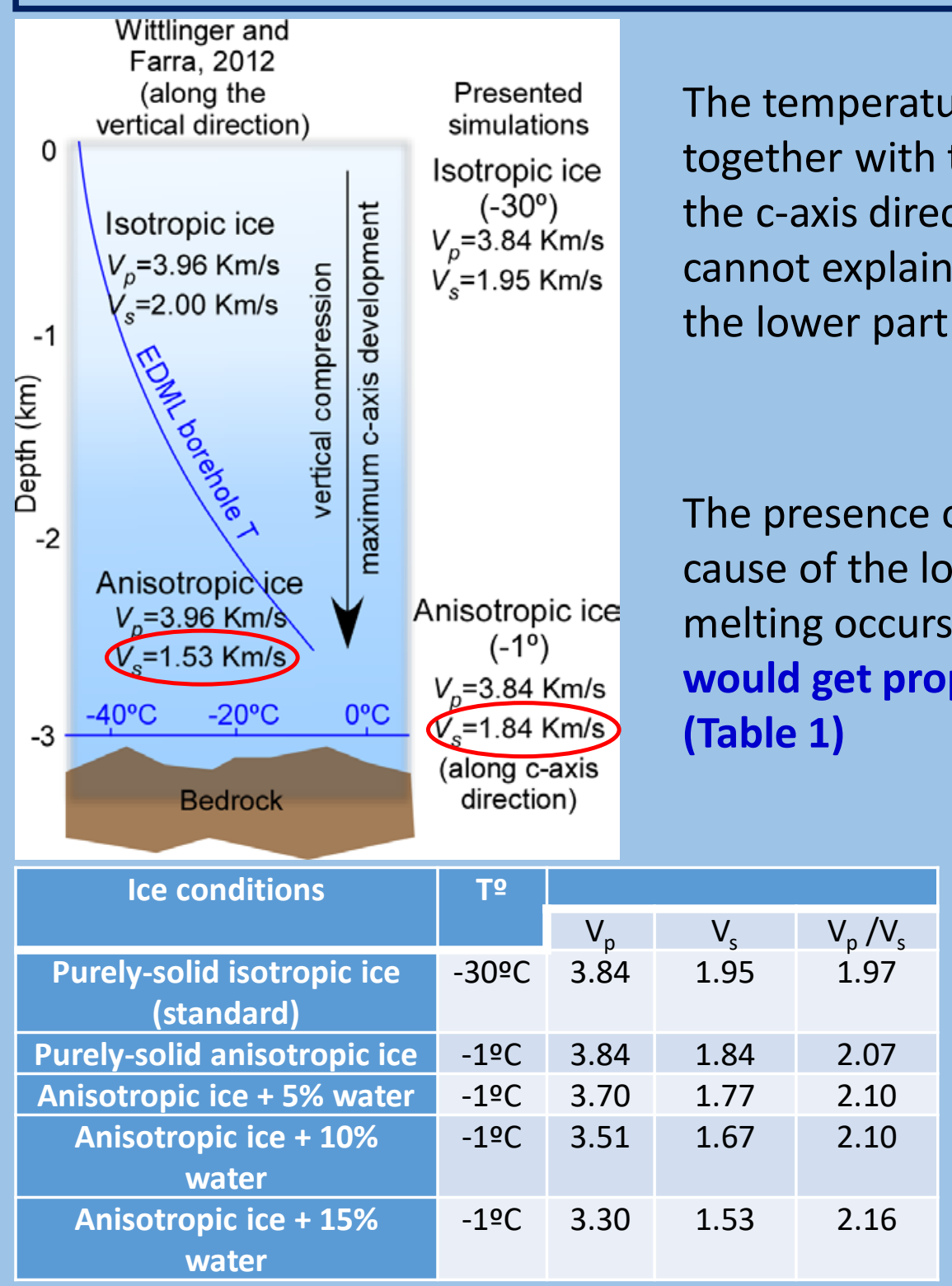

Table 1. Predicted Vp and Vs assuming the water bulk modulus for the melt phase. 


\section{Calculation of $\mathrm{P}$-wave and S-wave velocities}

\begin{tabular}{|c|c|c|c|c|}
\hline \multirow{2}{*}{ Ice conditions } & \multirow[t]{2}{*}{ T우 } & & & \\
\hline & & $V_{p}$ & $\mathrm{~V}_{\mathrm{s}}$ & $V_{p} / V_{s}$ \\
\hline $\begin{array}{c}\text { Purely-solid isotropic ice } \\
\text { (standard) }\end{array}$ & $-30 \div C$ & - & - & - \\
\hline Purely-solid anisotropic ice & $-1 \stackrel{\circ}{-C}$ & - & - & - \\
\hline Anisotropic ice + $5 \%$ water & $-1 \stackrel{\circ}{ } \mathrm{C}$ & 3.84 & 1.77 & 2.17 \\
\hline $\begin{array}{c}\text { Anisotropic ice }+10 \% \\
\text { water } \\
\end{array}$ & $-1 \stackrel{\circ}{ } \mathrm{C}$ & 3.83 & 1.66 & 2.31 \\
\hline $\begin{array}{l}\text { Anisotropic ice }+15 \% \\
\text { water } \\
\end{array}$ & $-1 \stackrel{\circ}{ } \mathrm{C}$ & 3.80 & 1.54 & 2.46 \\
\hline
\end{tabular}

Table 2. Predicted Vp and Vs assuming ice bulk modulus at -1 으 for both ice and melt phase.

The presented simulations are located at the transition between the deformation- and the recrystallisation-controlled regime, where water is located in isolated pockets and not forming water pocket networks. At this undrained conditions the bulk modulus of the water and ice aggregate must tend to the ice bulk modulus. If we assume this condition, Vs is significantly reduced proportionally to the presence of water, while $\mathrm{Vp}$ is only slightly reduced (Table 2 ). That would correspond to a thermomechanical regime of warm-based ice-sheet but with a thin temperate layer, where most of the deformation is internal and can be described by a standard power law flow law.

However, if we consider that the dynamic conditions in the lower part of the ice sheets correspond to the deformation-dominated regime, recrystallisation is too slow to counteract the shearing of water pockets and pockets get stretched continuously. Melt films located on grain boundaries will modify and even overprint the CPO-dependent orientation and magnitude seismic anisotropy. 